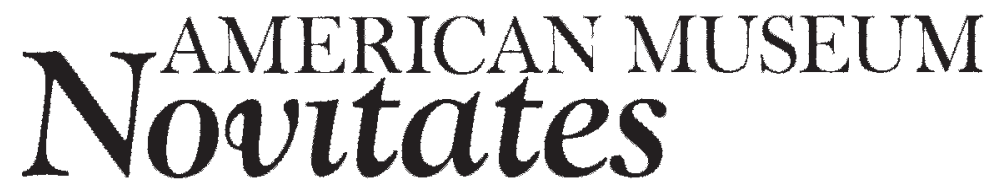

PUBLISHED BY THE AMERICAN MUSEUM OF NATURAL HISTORY CENTRAL PARK WEST AT 79TH STREET, NEW YORK, NY 10024 Number 3551, 8 pp., 9 figures

\title{
Tyrannoscelio, a New Genus of Neotropical Scelionidae (Hymenoptera: Platygastroidea) with Description of Two New Species
}

\author{
LUBOMÍR MASNER, ${ }^{1}$ NORMAN F. JOHNSON, ${ }^{2}$ AND \\ TANIA MILENA ARIAS-PENNA ${ }^{3}$
}

\begin{abstract}
Tyrannoscelio, new genus is described from the Neotropics (type species: T. genieri, new species). The position of the genus within the Scelioninae is unclear, but the presence of a well-developed skaphion suggests a relationship with Psilanteridini, Thoronini, or Parascelionini. Tyrannoscelio is characterized by a strongly produced frontal ledge and enormously elongate mandibles. Two species are described in the genus: T. genieri, new species from Brazil (Espírito Santo), and $T$. crenatus, new species from Colombia (Caquetá).
\end{abstract}

\section{INTRODUCTION}

Species of several genera of Scelionidae have the dorsal portion of the frons expanded and produced anteriorly to form a protruding shelf. These genera include Sparasion Latreille (Sparasionini), Acanthoscelio Ashmead (Scelionini), Encyrtoscelio Dodd (Gryonini), and Breviscelio Sundholm (Gryonini). This character is widely distributed within the family and is undoubtedly multiply derived. The frontal shelf is typically, but not strictly, found in taxa that parasitize eggs that are laid in the soil (Caleca and Bin, 1995; Grissell, 1997) and may be associated with digging. We report herein the discovery of a new genus of Scelionidae, Tyrannoscelio, n.gen., in another clade of the family that also possesses a welldeveloped frontal shelf. In this case, though, the shelf is unique in that the anterior margin is produced into strong, upcurved projections. There are two distinct species found in widely

\footnotetext{
${ }^{1}$ Agriculture and Agri-Food Canada, Research Branch, K.W. Neatby Building, Ottawa, Ontario K1A 0C6, Canada.

${ }^{2}$ Department of Entomology, The Ohio State University, 1315 Kinnear Road, Columbus, OH 43212 (johnson.2@ osu.edu).

${ }^{3}$ National University of Colombia, Bogotá, DC, Colombia (tmariasp@unal.edu.co).
} 
separated parts of South America, suggesting that focused collecting in suitable habitats may reveal even more diversity.

\section{MATERIALS}

This work is based on specimens in the following collections:

CNCI A. Bennett: Canadian National Collection of Insects, Agriculture and Agri-Food Canada, Ottawa, Canada

IAVH Instituto de Investigación en Recursos Biológicos Alexander von Humboldt, Boyacá, Colombia

MZSP C.R.F. Brandão: Museu de Zoologia da Universidade de São Paulo, São Paulo, Brazil

OSUC N.F. Johnson: The Ohio State University Insect Collection, Columbus, $\mathrm{OH}$

UFES C.O. Azevedo, Universidade Federal do Espírito Santo, Departamento de Biologia, Vitória, Espírito Santo, Brazil

Abbreviations and terms used in text include: A1, A2, ... A12: antennomere 1, 2, .. 12; claval formula: distribution of the large, multiporous basiconic sensilla on the underside of apical antennomeres of the female, with the segment interval specified followed by the number of sensilla per segment (e.g., A8A12 1-2-2-2-1; Bin, 1981); OOL: ocular ocellar line, shortest distance from inner orbit and outer margin of posterior ocellus (Masner and Huggert, 1989); epomial carina: the vertical portion of epomium on the pronotum; pronotal humeral carina: the horizontal portion of epomium on the pronotum; S1, S2, ... S6: metasomatic sternum $1,2, \ldots 6$; T1, T2, .. T7: metasomatic tergum $1,2, \ldots 7$.

\section{Tyrannoscelio Masner, Johnson, and Arias-Penna, new genus figures 1-9}

DESCRIPTION: Length $3.1-4.2 \mathrm{~mm}$; body cylindrical, almost cigar-shaped, with relatively short legs, antenna; head massive; mesosoma, metasoma normally proportioned; head, metasoma dark brown to black, mesosoma dark brown to rufous; macropterous.
Head (figs. 1-6) remarkably large, distinctly longer than wide in dorsal view, length 1.5-1.6 times greatest width; upper frons strongly produced anteriorly into shelf (figs. 3, 4: fs), anterior margin produced into upcurved, truncate projections; hyperoccipital carina absent; occipital carina well developed, continuous medially, finely crenulate; lateral ocellus close to inner orbit of compound eye, OOL short, less than diameter of lateral ocellus (figs. 1, 5, 6); compound eye large, with scattered elongate setae (fig. 5); frons largely flat or weakly concave, smooth, glabrous medially; area between compound eye, antennal insertion, and base of mandible deeply concave, corresponding to shift in position of anterior mandibular articulation, with arched rugulae parallel to base of mandible, moderately setose; interantennal process strongly produced anteriorly, torulus opening laterally from process; submedian carina absent; orbital carina present, extending along inner orbit, ventrally continuing toward posterior mandibular articulation; lower frons without fanlike striae; interocular space broad; inner orbits parallel; clypeus strongly raised beneath interantennal process; anteclypeus divided from postclypeus by strong arcuate carina, anteclypeus transverse, convex, dorsoventrally carinate, with four elongate setae arising from apical margin; postclypeus smooth, concave, apical margin strongly concave; malar sulcus absent; gena greatly expanded, convex, lower margin deeply notched at position of posterior mandibular articulation; labrum hidden beneath clypeus; mandible (figs. 2, 3, 4: md) extremely long, directed anteriorly, anterior articulation deeply invaginated, posterior articulation shifted anteriorly to side of head, mandibular range of movement primarily dorsoventral, with weak transverse component; mandible with numerous strongly developed teeth along both inner and outer margins; maxillary palpus four-segmented, all segments cylindrical; labial palpus two-segmented; antenna 12 merous in both sexes; radicle inserted apically into A1, nearly parallel to longitudinal axis of A1; A1 widest basally, gradually narrowed toward apex; A3 longer than A2; apical six antennomeres expanded into clava in female; gustatory sensilla on female antenna arranged in 

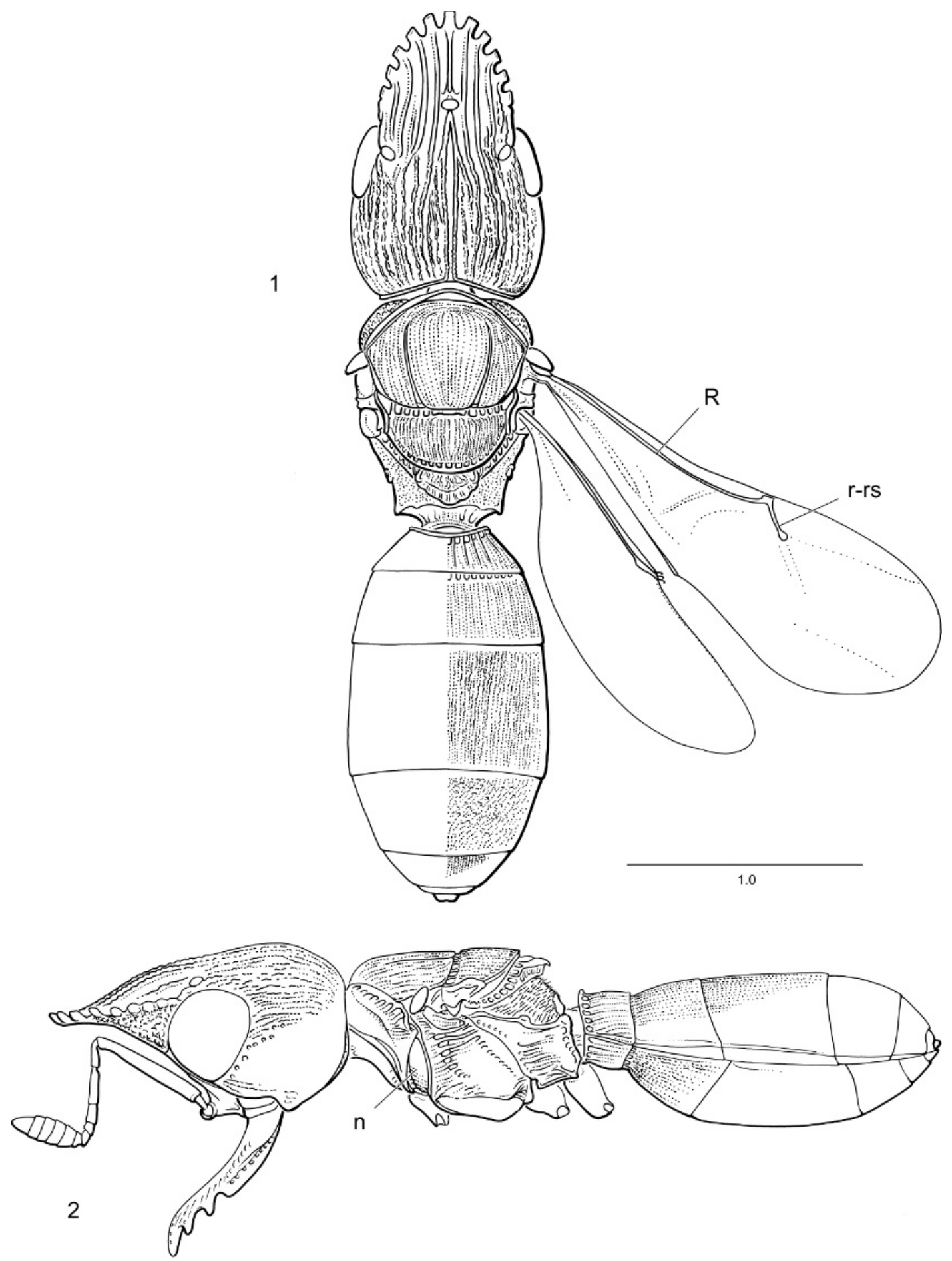

Figs. 1, 2. Tyrannoscelio genieri, n.sp., holotype female (OSUC 147597); 1, Dorsal habitus. 2, lateral habitus. n, netrion; R, radial vein (submarginal vein); r-rs, radial-radial sector crossvein (stigmal vein). Scale bar in millimeters. 


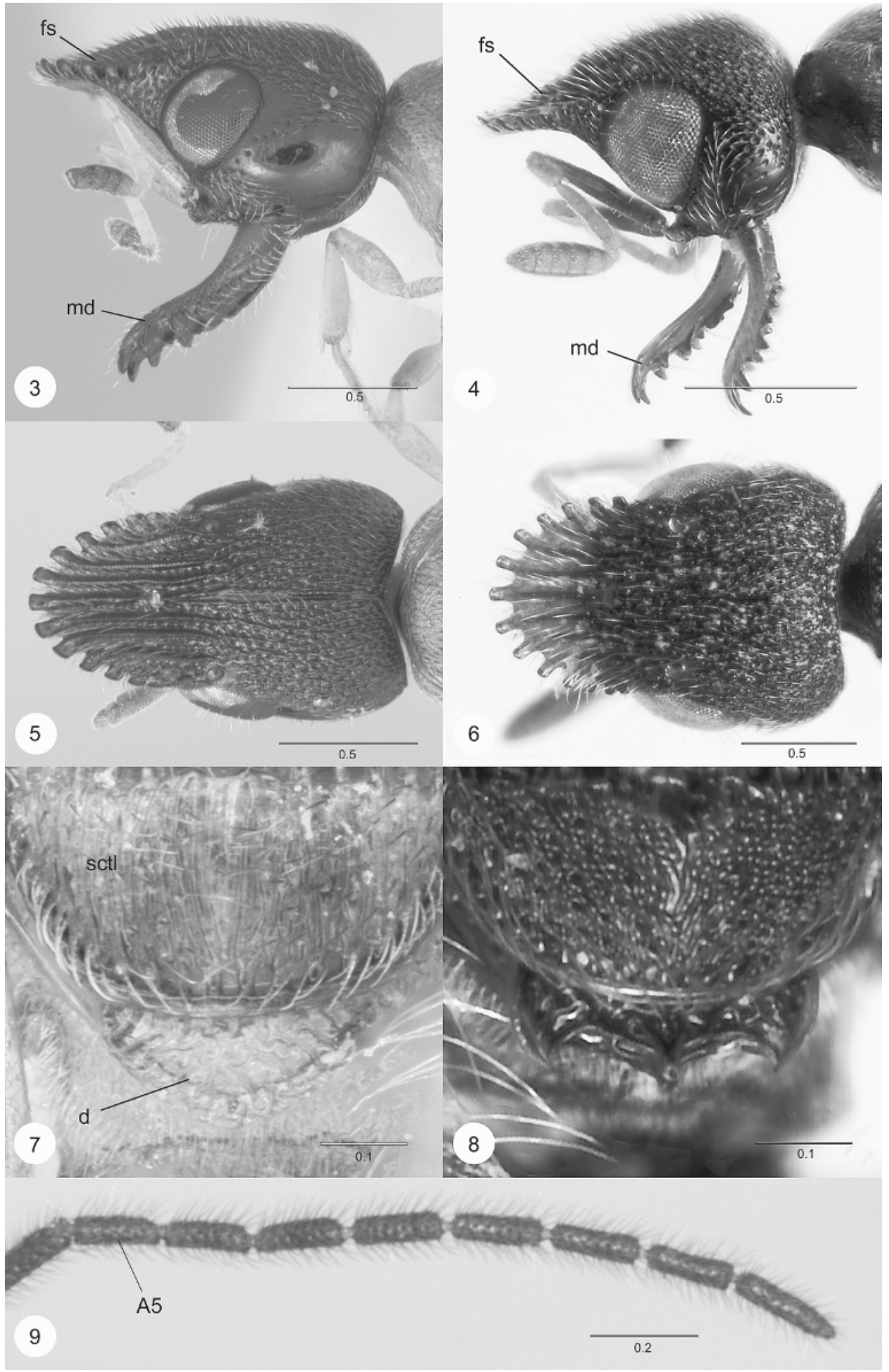


longitudinal pairs on apical antennomeres; claval formula A8-A12 1-2-2-2-1; male antenna (fig. 9) without visible tyloids or differentiated sex segment, flagellomeres cylindrical, each constricted basally and apically, with erect setae.

Mesosoma (figs. 1, 2) cylindrical, in dorsal view longer than wide, in lateral view deep, somewhat flattened dorsally; pronotum in dorsal view narrow laterally, anterolateral corners rounded; transverse pronotal carina absent; epomial carina absent; pronotal humeral carina present; anterior face of pronotum extremely narrow, hidden in dorsal view; lateral face of pronotum largely flat to weakly concave, facing anteriorly, without scrobe for reception of foreleg; netrion (fig. 2: n) very broad, as wide as tegula, fusiform, open ventrally; anterior margin of mesoscutum meeting pronotum anteriorly, not dorsally; mesoscutum semioval in outline; parapsidal lines absent; notauli present, nearly percurrent or abbreviated; skaphion present, narrow, posterior margin strongly carinate; transscutal articulation well developed, crenulate; scutellum (figs. 7, 8: sctl) wider than long, unarmed, convex, weak medial longitudinal furrow; axilla well developed; metanotum narrow, dorsellum (figs. 7, 8: d) clearly differentiated, produced into flat lamella, apical margin variable in armature; dorsal surface of propodeum with dense, fine pilosity; keels, plicae of propodeum not developed; posterior face of propodeum punctate, setose; mesopleuron large, prominent; mesopleural depression well developed; mesopleural carina indicated by line of crenulae or short, parallel longitudinal rugulae; sternaulus absent; mesopleural pit present, shallow; anterior margin of ventral portion of mesepisternum straight, not protruding between forecoxae; mesepisternum and mesepimeron separated by line of welldeveloped foveae; episternal foveae absent; dorsal corner of mesepimeron rounded, with- out posterior tooth; anteroventral portion of metapleuron rounded, not separated from lateral face by carina, setose; metapleural pit absent; posterior margin of metapleuron lamellate; metapleuron separated from propodeum dorsally by deep groove; propodeum without longitudinal carinae, setose throughout, posterolateral corners weakly projecting posteriorly; legs relatively slender; posterior surface of hindcoxa smooth; femora not incrassate; trochantellus present on all legs; outer surface of foretibia and midtibia with strong semierect spines; tibial spur formula 1$1-1$, tarsal formula 5-5-5; tarsomeres tapering in width apically, second tarsomere for foretarsus rather short; pretarsal claws simple; apex of forewing extending to $\mathrm{T} 4$ or beyond, moderately infuscate, marginal cilia short but distinct; $\mathrm{R}$ fairly straight, extending through basal 0.5 of length of forewing, extending to costal margin, with strong bristles arising throughout its length, costal portion (marginal vein) very short, nearly punctiform, wing membrane around this point infuscate, forming pseudostigma; $R_{1}$ absent or extremely short, therefore without postmarginal vein; rrs (stigmal vein) straight, arising from costal margin; no other tracheate veins in forewing; hindwing with $\mathrm{R}$ tracheate throughout its length, extending to hamuli and costal margin; no strong dark bristles on $\mathrm{R}$; three hamuli present.

Metasoma (figs. 1, 2) more or less cylindrical, terga slightly flattened, sterna deep, convex; T3 distinctly the longest tergite; female with 7 terga, 6 sterna visible externally, male with 8 terga, 7 sterna visible externally; submarginal ridge well developed, defined by narrow laterotergites to form deep submarginal rim; no spiracles visible; anterior margin of segment 1 deeply crenulate; suture between segments 1 and 2 basally crenulate; sutures between other segments simple; female T6 without median raised field of microsetae or

Figs. 3-9. Tyrannoscelio spp. 3, T. genieri, n.sp., holotype female (OSUC 147597), head, lateral view; 4, T. crenatus, n.sp., paratype female (OSUC 148938), head, lateral view; 5, T. genieri, n.sp. (OSUC 147597), head, dorsal view; 6, T. crenatus, n.sp. (OSUC 148938), head, dorsal view; 7, T. genieri, n.sp. (OSUC 147597), scutellum and metanotum, dorsal view; 8, T. crenatus, n.sp. (OSUC 148938), scutellum and metanotum, dorsal view; 9, T. genieri, n.sp., male antenna, A4-A12 (left to right). A5, fifth antennomere; d, dorsellum; fs, frontal shelf; md, mandible. Scale bars in millimeters. 
secretion; S1 arched, not laterally compressed, not extending anteriorly between hindcoxae; anterior margin of S2 straight; narrow sublateral felt fields present on S2; ovipositor not dissected.

Diagnosis: Distinguished from Sparasion by the 1-1-1 tibial spur formula, lack of bulla in $\mathrm{R}$ (submarginal vein), lack of a postmarginal vein; distinguished from Acanthoscelio by the well-developed, distinct forewing venation, the complete $\mathrm{R}$ in the hindwing extending to the hamuli, and the semicircular scutellum lacking lateral spines; distinguished from Encyrtoscelio and Breviscelio by the elongate metasoma with T3 being the longest tergite. Additionally, Tyrannoscelio can be separated from all these genera by the presence of a narrow skaphion at the anterior part of the mesoscutum.

Type Species: Tyrannoscelio genieri Masner and Johnson, new species.

Eтумоlogy: From tyranno-, master or despot, and scelio, the name for the nominal genus of the family, alluding to both its formidable head and that of the theropod Tyrannosaurus.

Geographic Distribution: Neotropical, known from southeast Brazil (Espírito Santo) and Colombia (Caquetá).

Comments: Tyrannoscelio does not fit naturally into the current, uncertain tribal classification of the Scelionidae. Three characters stand out as being of possible significance in assessing its relationships: the presence of a skaphion, the absence of a malar sulcus, and the absence of a sex segment in the male antenna.

The skaphion is an anterior subdivision of the mesoscutum. It is found in all genera of the Thoronini (sensu Masner, 1972), but is also scattered among other genera, including Parascelio Dodd (the only genus within the Parascelionini) and many Psilanteridini sensu Masner (1976). Austin and Field (1997) strongly suggested that Psilanteridini is not monophyletic, and they provided evidence for a major monophyletic group within the Scelioninae, the Scelionini sensu lato, united on the basis of a suite of characters from the ovipositor. (We chose not to sacrifice one of the few female specimens of Tyrannoscelio in order to dissect the ovipositor, the character suite used to define Scelionini s.1.) When mapped onto their consensus cladogram (Austin and Field, 1997: fig. 189), the skaphion appears in seven different lineages. Even when some of these are clustered together on the basis of this character, it appears that the skaphion has either appeared or disappeared at least three times in the course of scelionid evolution.

The malar sulcus, extending from the lower portion of the compound eye to the base of the mandibles, is a feature present in practically all Scelionidae. It is notably absent, however, in several of the genera usually considered to be basal within the family: Archaeoscelio Brues (an extinct genus from Baltic amber), Nixonia Masner, Sparasion Latreille, Sceliomorpha Ashmead, Plaumannion Masner and Johnson, Huddlestonium Polaszek and Johnson, as well as in practically all genera of Platygastridae (all except Metaclisis Förster and Orseta Masner and Huggert). We consider it likely that the absence of a malar sulcus is plesiomorphic. Thus, its absence in Tyrannoscelio implies either that the genus must be excluded from a group comprising most scelionids, or that the sulcus has been secondarily lost, possibly in concert with the development of the other striking modifications of its head structure.

Finally, almost all scelionid and platygastrid males have one or more antennomeres modified into a so-called "sex-segment." This segment is usually A5 in scelionids and A4 in platygastrids, and the "basal" genera Archaeoteleia Masner, Nixonia, Sparasion, and Sceliomorpha often have several antennomeres (up to five, from A4 to A8) bearing tyloids. Tyrannoscelio is one of very few species in the superfamily in which there appears to be no such modification. Notably, one of these is Archaeoscelio, although we must admit that this may be an artifact arising from the difficulty of observing minute features in amber material.

\section{Key to Species of TyranNoscelio}

1. Mesoscutum and scutellum longitudinally rugose; notauli nearly percurrent; dorsellum semicircular; apical margin of frontal ledge with 10 projections; outer margin of mandible with three teeth (Brazil) . . . . . . . . . . . ...... T. genieri Masner and Johnson, n.sp. 
- Mesoscutum and scutellum punctate-rugulose; notauli very short; dorsellum tridentate; apical margin of frontal ledge with 14 projections; outer margin of mandible with five to six teeth (Colombia) ... T. crenatus Arias-Penna, n.sp.

\section{Tyrannoscelio genieri Masner and Johnson, new species \\ figures $1-3,5,7$}

Description: Holotype female: Length: $4.2 \mathrm{~mm}$; head, metasoma dark brown to black; anterior margin of frontal ledge, mandibles, A8-A11 brown; mesosoma light brown; legs, A1-A7 pale yellow.

Head large, elongate, length 1.6 times width; vertex rugulose punctate, sculpture with strong longitudinal orientation, covered with numerous semidecumbent setae, medially with longitudinal furrow extending from occipital carina to median ocellus; frontal ledge strongly produced, with 11 longitudinal costulae, between costulae with line of setigerous punctures, anterior margin of ledge produced into 10 upcurved, truncate projections, lower surface of projections smooth, setose; upper portion of gena longitudunally rugulose, otherwise largely smooth, with sparse setose punctures near eye; mandible long, sigmoid, apical half dentate, outer margin with three acute, ventrally directed teeth, inner margin with two acute teeth, long truncate basal tooth, apex of mandible spatulate.

Mesosoma height 1.5 times width; mesoscutum finely, longitudinally costulate, covered with fine dark setae; notauli present, fine, nearly percurrent; scutellum longitudinally costulate, covered with fine dark setae; dorsellum in form of semicircular lamella, without armature; forewing extending to apex of T4.

Metasoma length 2.0 times greatest width; T1 longitudinally costate, with simple line of setae along lateral margin; T2 longitudinally costulate, largely glabrous medially, finely setose laterally; T3 longitudinally costulate with superimposed coriaceous microsculpture, setose throughout; T4-T6 shallowly punctate with coriaceous microsculpture, densely setose throughout; sensory bristles arising from cercus short.

Male: Nearly identical to female; somewhat smaller, length $3.5-4.0 \mathrm{~mm}$; A1-A2 pale yellow, A3-A12 dark brown; A3 much longer than A2; flagellomeres elongate, with erect setae, each flagellomere distinctly separated; mandible narrower; forewing extending posteriorly to apex of metasoma.

Diagnosis: Distinguished from $T$. $\mathrm{cre}$ natus by the semicircular dorsellum, the longitudinally costate mesoscutum and scutellum, the elongate notauli, the smaller number of mandibular teeth, and the smaller number of projections on the frontal ledge.

ETYMOLOGY: Named in honor of one of the earliest collectors of the type series, François Génier (Canadian Museum of Nature, Ottawa).

Material Examined: Holotype female: BRAZIL: Espírito Santo, 19 58'19.5'S $40^{\circ}$ $32^{\prime} 10.3^{\prime \prime} \mathrm{W}$, Linhares, Reserva Biológica Sooretama, 21-24.III.2002, ponto trilha 1, Möricke, C.O. Azevedo \& equipe col, OSUC 147597. Deposited in MZSP. Paratypes: BRAZIL: Espírito Santo, $19^{\circ} 58^{\prime} 19.5^{\prime \prime S} 40^{\circ}$ $32^{\prime} 10.3^{\prime \prime} \mathrm{W}$, Linhares, Reserva Biológica Sooretama, ponto trilha 3, 21-24.III.2002, Malaise, C.O. Azevedo \& equipe col., 5 males (OSUC 147592, 147593, 147594, 147595, 147596); ponto trilha 1, Malaise, 1 male (OSUC 147600); ponto trilha 1, Möricke, 1 male (OSUC 147599); ponto Bosque 6, Malaise, 1 male (OSUC 147589); 24-27.III.2002, ponto trilha 1, Möricke, 2 males (OSUC 147598, 147607); 06.IV.2002, amostra \#1, Varredura [sweeping], 2 males (OSUC 147585, 147586). $19^{\circ} 03^{\prime} 50^{\prime \prime} \mathrm{S} 39^{\circ} 58^{\prime} 43^{\prime \prime} \mathrm{W}$, Município de Linhares, Fazenda Lagoa do Macuco; 10 m; 28.I.2000-51, F. Génier \& S. Ide, primary lowland Atlantic forest, sandy soil, ex. f.i.t. 1-3, day 4; 1 male, 1 female (OSUC 148932, 148933). $19^{\circ} 08^{\prime} 50^{\prime \prime} \mathrm{S}$ $39^{\circ} 58^{\prime} 43^{\prime \prime} \mathrm{W}$; Municíp. Linhares, $10 \mathrm{~m}$; 28.I. 2000, F. Génier; Atlantic for.; FIT, 1 male, 1 female (OSUC 148934, 148935). 20 04'27,9'S $40^{\circ} 44^{\prime} 51,3^{\prime \prime} \mathrm{O}$ [W], Sta. Maria de Jetiba-Fazenda Clarindo Grüger; 06-13.XII.2002, Malaise T5, Tavares, Azevedo \& eq. col., 2 males (OSUC 148936, 148937). Cariacica, Res. Biol. Duas Bocas, 04.X.1996, Möricke, Azevedo \& equipe, col.; 2 males (OSUC 163999, 163400). (CNCI, MZSP, OSUC, UFES)

\section{Tyrannoscelio crenatus Arias-Penna, new species \\ figures $4,6,8$}

DesCRIPTION: Holotype female: Length: $3.1 \mathrm{~mm}$; head, scutellum, metanotum, propo- 
deum, netrion, metapleuron dark brown; anterior margin of frontal ledge, mandibles, pronotum, mesonotum, propleuron light brown; antenna, legs yellow; metasoma predominantly dark brown, lighter medially.

Head globose, length 1.5 times width; vertex rugulose punctate covered with decumbent setae; frontal ledge strongly produced with 10 longitudinal costulae, between costulae transversely subdivided by sculpture, anterior margin produced into 14 upcurved, obtuse projections, lower surface of projections smooth; upper portion of gena rugulose punctuate, otherwise largely smooth, with sparse punctures; mandible long, sigmoid, apical twothirds dentate, outer margin with five to six acute, ventrally directed teeth, inner margin with two acute teeth, apex of mandible acute.

Mesosoma height 1.4 times width; mesoscutum densely punctuate, covered with decumbent hairs; notauli abbreviated; scutellum rugulose-punctate, covered with sparse, erect hairs; dorsellum tridentate, teeth short, subequal in length, lateral teeth curved medially; forewing extending to T5.

Metasoma length 2.1 times greatest width; T1 longitudinally costate; T2 longitudinally costate medially, rugulose-punctate laterally, largely glabrous medially, setose laterally; T3T4 medially and along anterior margin smooth, otherwise punctate with coriaceous microsculpture, finely setose; T5-T6 punctate with coriaceous microsculpture, densely setose throughout; cercus with long sensory bristles.

Male unknown.

Diagnosis: Distinguished from $T$. genieri by the tridentate dorsellum, the punctate mesoscutum and scutellum, the short notauli, the greater number of mandibular teeth, and the greater number or projections on margin of the frontal ledge.

ETYMOLOGY: From the Latin crenatus, notched or toothed, referring to the anterior margin of the frontal ledge.

Material Examined: Holotype female: COLOMBIA: $0^{\circ} 10^{\prime} 47^{\prime \prime} \mathrm{N} \quad 72^{\circ} 27^{\prime} 24^{\prime \prime} \mathrm{W}$, Caquetá, Solano, PNN Serranía de Chiribiquete, Río Sararamano, bosque tierra firme, $250 \mathrm{~m}$, pitfall T1-T1, 05.IV.2000, E. González. Deposited in IAVH. Paratype: COLOMBIA: $0^{\circ} 32^{\prime} 04^{\prime \prime} \mathrm{N} 72^{\circ} 37^{\prime} 57.5^{\prime \prime} \mathrm{W}$, Caquetá, Solano, PNN Serranía de Chiribiquete,
Río Cuñare, bosque tierra firme, $250 \mathrm{~m}$, pitfall T2-T3, 17-19.XI.2000, E. González \& M. Ospina, 1 female (OSUC 148938). (CNCI)

\section{ACKNOWLEDGMENTS}

We thank A.P. Aguiar (São Paulo) for sorting scelionids from more than one thousand BiotaSP samples and to C.R.F. Brandão (São Paulo) for making this material available for study; L. Musetti for comments on the manuscript, specimen preparation, database support, and general encouragement; J. Cora for database support; S. Westby for the line drawings; and K. Bolte for images of Tyrannoscelio crenatus. This material is based on work supported in part by the National Science Foundation under grant DEB-0344034.

\section{REFERENCES}

Austin, A.D., and S.A. Field. 1997. The ovipositor system of scelionid and platygastrid wasps (Hymenoptera: Platygastroidea): comparative morphology and phylogenetic implications. Invertebrate Taxonomy 11: 1-87.

Bin, F. 1981. Definition of female antennal clava based on its plate sensilla in Hymenoptera Scelionidae Telenominae. Redia 64: 245-261.

Caleca, V., and F. Bin. 1995. World revision of the genus Encyrtoscelio Dodd (Hymenoptera: Scelionidae). Invertebrate Taxonomy 9: 10211045.

Grissell, E.E. 1997. Biological notes on Sparasion Latreille (Hymenoptera: Scelionidae), an egg parasitoid of Atlanticus gibbosus Scudder (Orthoptera: Tettigoniidae). Proceedings of the Entomological Society of Washington 99: 693-696.

Masner, L. 1972. The classification and interrelationships of Thoronini (Hymenoptera: Proctotrupoidea, Scelionidae). The Canadian Entomologist 104: 833-849.

Masner, L. 1976. Revisionary notes and keys to world genera of Scelionidae (Hymenoptera: Proctotrupoidea). Memoirs of the Entomological Society of Canada 97: 1-87.

Masner, L., and L. Huggert. 1989. World review and keys to genera of the subfamily Inostemmatinae with reassignment of the taxa to the Platygastrinae and Sceliotrachelinae (Hymenoptera: Platygastridae). Memoirs of the Entomological Society of Canada 147: $1-214$. 